\title{
EDUCATORS' PROFESSIONAL AND PERSONAL GROWTH: A CASE STUDY OF EUROPEAN TEACHERS' IN-SERVICE TRAINING COURSES
}

\author{
Ulla Salomäki, Inkeri Ruokonen and Heikki Ruismäki \\ University of Helsinki, Finland
}

\begin{abstract}
In this paper, we consider the development of teachers' emotional skills by using arts and skills. In the theoretical background, we focus on the modern theories of motivation, learning and school culture and on cultural theories (Sapher \& King, 1985) of school environments and views of learning. The main problem is to determine which skills the teachers can achieve during intensive training of emotional skills and arts. In the paper, we have used the course evaluations and post-evaluation material from one of the Comenius courses held in Cyprus in October 2008. The findings show that, in spite of the school culture, all the methods for teaching emotional skills can also be used for the personal and professional growth of teachers. Teachers' well-being and a positive school environment are essential in sustainable development and education.
\end{abstract}

Key words: self-regulation, emotional skills, arts education, teachers' personal and professional growth, in-service training

\section{Introduction}

The Comenius European In-Service Training Courses are organised as part of the European Union Life Long Learning (LLP) programme under the decentralised action. Before the courses are organised, they have to be developed in Comenius Multilateral projects (previously in Comenius 3.1. or 2.1.projects).

The Comenius programme focuses on all phases of education, from pre-school to primary and secondary schools. It is relevant for all members of the education community: pupils, teachers, local authorities and all the other educational staff along with parents' associations, non-government organisations, teacher training institutes and universities. The programme addresses issues strongly related to current discussions and developments in school policy, and the priorities are set annually.

The background of the European Courses in this research is the Comenius 3.1. Project on Group Dynamics and Social Skills in the Classroom (1999-2001). In this project, the innovative element was beginning the development of arts and skills methods that all educators could use in learning situations. The Finnish Centre for Health Promotion coordinated the project, and the partner institutions were Hogeschule of Jönköping in Sweden and the 
University of Lüneburg in Germany. When the project was finished, the European Bridges Consultancy (EBC) from Finland began to organise Comenius European courses related to the aforementioned project in cooperation with educational institutions in different countries. By the beginning of the year 2012, the EBC has organised 30 courses, 12 of them before 2009 and 18 - after that. The total of 534 participants took the courses from 2002 till 2012. The European Union (EU) selected this project to present the European Comenius success stories in 2008.

The EBC has organised six different courses: (1) group dynamics and social skills in the classroom; (2) action methods improving motivation and quality in the learning environments; (3) stress management in the schools; (4) motivating and mentoring the novice teacher; (5) relationship and sexual education in the schools and (6) seeking excellence in teaching, learning and studying practices.

The Comenius courses are intensive and last a minimum of seven days. The courses are funded by grants, which the participants have applied for and received from their National Agencies for the LLP programme.

The course in this case study $(\mathrm{N}=11)$ was held in the Elia Holliday Village in the village of Latchi, Cyprus, in October 2008. The aims of the course were to create a 'laboratory situation' in which to study and observe the group process and cohesion during the course of one week and to learn how to improve the motivation in learning environments.

\section{Theoretical background}

The ability to monitor and reflect on emotions is part of emotional intelligence (Salovey, Bedell, Detrweiler, \& Mayer, 2004). Reflective thinking refers to the processes of analysing and making judgments about what has occurred. Dewey $(1938 / 1997)$ suggests that reflective thinking is an active, persistent and careful consideration of a belief or a supposed form of knowledge, the rationale that support that knowledge and the further conclusions to which that knowledge leads. Learners are aware of and control their learning by actively participating in the reflection and assessment of what they know, what they need to know and the ways in which they bridge that gap during learning situations.

Learners are self-regulated to the degree that they are cognitively, motivationally and behaviorally active participants in their own learning processes (Zimmerman, 1990, 2000; Pintrich, 2000). Research has demonstrated that only a fraction of learners across a wide range of ages are self-regulated (Azevedo \& Cromley, 2004). The rest lack the knowledge and skills they need to effectively manage their learning. It has been suggested that, although selfregulated learning is not spontaneously acquired, it may be shaped and developed through participation in the environments that provide learners with opportunities to be in control of their own learning (Zimmerman, 1990, 2000). According to Gardner (1993), intrapersonal intelligence is the key to self-knowledge, including access to feelings and the ability to discriminate among them and draw upon them to guide behavior.

The modern theory of motivation represented by Deci and Ryan (2000) indicate that 'tricks 
and recipes' are not effective in the improvement of motivation, but, instead, a wide understanding of motivation, emotion, cognition and their relations can help. When educators are asked to describe the characteristics of the best teacher, the list is as follows: the best teacher is empathetic, has a good sense of humor, is inspired by his/her work, is a good listener, is ready to face the new, uses different teaching methods and has a strong knowledge of the subject and pedagogy. It is not difficult to imagine that this kind of educator knows how to motivate both students and him/herself to work. If we made a list of the opposite characteristics, we would get a picture of a control-oriented, authoritarian teacher whose main pedagogical aim was to keep the pupils silent so that he/she could pour ready-made thoughts into them.

The foundation of self-regulation and inner growth is built on three basic psychological needs: competence, relatedness and autonomy. All are essential for facilitating optimal functioning of the natural inclinations for growth and integration as well as constructive social development and personal well-being (Ryan \& Deci, 2000). In control-oriented learning environments, where the pupils are passive recipients, these basic needs are neglected. If a pupil copies and memorises ready-made thoughts and solved problems, he/she will not develop or recognise his/her competences; if interaction in the classroom is forbidden, there is no feeling of relatedness, and, if independent thinking and choice making are restricted, the need for autonomy is neglected as well. It does not mean that the needs no longer exist; instead, they reveal themselves in restless behaviour, fatigue, concentration problems and daydreaming all signs of unmotivated behaviour.

Research results have shown the effectiveness of teaching and teacher training approaches and learning environments that integrate subject-matter knowledge and self-regulation skills (Butler \& Cartier, 2004; Schraw, Crippen, \& Hartley, 2006). Therefore, educators and researchers believe that teachers' ability to cultivate learners who are self-regulated during learning is tied to teachers' own self-regulation. If teachers are incapable of self-regulating their own being and learning, they will have difficulty developing these capabilities in their students.

In recent years, developing more sustainable learning environments has become one of the global educational aims. The understanding of the concept of sustainability has been established; it consists of three dimensions: environmental protection, economic stability, social considerations and well-being (Steiner $\&$ Posh, 2006). Fleer's (2002) study also indicated that even the youngest children articulated a view about their environment featuring social issues. We believe that educational empowerment and sustainable changes in learning environments start from good team work where every person is respected and loved as an individual. Hopkins and McKeown (2002) emphasise that pre-service and in-service teacher training is essential in building new settings in the school curriculum and learning environment as well as in enhancing cooperation between communities in formal and informal learning.

According to Steiner and Posh (2006), interdisciplinary teaching does not focus primarily on detailed factual knowledge; rather, it focuses on the development of core competencies for solving different kinds of problems. Students' social competencies, such as effective communication, presentation skills and teamwork, frequently need to be improved. Moreover, such 
methodological competencies as traditional project management techniques and more complex planning and decision-making methods need to be accomplished. Thus, students also 'learn how to learn', and this should be a fundamental goal of any education and certainly of education for sustainable development (White, 2001). Such an interdisciplinary approach that was present in this research setting calls for cooperation across different subjects, disciplines and pedagogical ways of thinking.

According to Saphier and King (1985), the cultural norms that affect the school environments' improvement are collegiality, experimentation, high expectations, trust and confidence. They also emphasise tangible support, reaching out to the knowledge bases, appreciation and recognition, caring, celebration and humour. Involvement in decision-making, protection of what is important, traditions, honest and open communication are also important factors in the educational setting. We agree that these are the main keys in building a socially sustainable and a positive school environment.

Consequently, programmes to enhance teachers' professional and personal growth should promote the self-regulation skills acquired in the pedagogical context. Such programmes should afford opportunities for developing practices associated with supporting self-regulation as well as developing knowledge and skills that will enhance teachers' selfregulation in their own learning and teaching (Randi \& Corno, 2000; Randi, 2004).

However, studies have indicated that teachers come to any training programme with prior experiences, knowledge and perceptions about teaching and learning. These prior perceptions often serve as a lens through which the teachers view the new pedagogical knowledge being taught and the new processes of teaching and learning they encounter. Therefore, it is essential that teacher educators take these prior perceptions into account when processing the new learning outcomes (Pajares, 1992).

\section{Study design}

\section{Aim and method of the study}

The approach of this research is qualitative. The study addresses two research questions: How can teachers' professional and personal growth be promoted? and What is the effect of the organised Comenius courses in different learning environments on such growth according to teachers' personal evaluations?

In this study, the data was collected using open-ended questionnaires that do not have set answers, but rather have the respondents frame their own responses, following a course organised in October 2008 in Cyprus. The title of the course was "Action Methods Improving Motivation and Quality in the Learning Environments". The research material was collected from 11 teachers participating in this research who come from seven EU countries: Belgium (1); Denmark (1); Finland (2); France (1); Germany (2); Lithuania (2); Spain (1) and Sweden (1).

The eleven respondents consisted of nine females and two males. Half of the respondents 
(six) were working in primary or secondary schools (one in special education) and the other half (five) in vocational and teacher training institutions. Three participants have worked fewer than ten years in their present job; four participants - 11-20 years; two participants 16-20 years and two participants $-20-30$ years. There were seven teachers, three headmasters or directors, one supervisor and one special education teacher.

The evaluation of the course was made in three parts. Before the course, the participants received a pre-evaluation form in which they were asked about their expectations from and goals for the course. At the end of the course, they filled in an evaluation form for the entire course, and, after six months, they received a post-evaluation form, in which they described the effect of the course on their school life and on themselves.

Thus, the collected data contains the participants' background information, their expectations from, needs for the course and the impact of the course. They were also asked about the effects of the course and their plans to use the learned tools and materials. Other questions were related to the effects of course experience on the pupils, the classroom, the entire school and the course participants as teachers and people. The research material was analysed by content analysis. In the content analysis of data, the phenomenographic analysis was carried out using the following procedure described by Marton (1994). As the writings of the teachers can be expressed in different units, such as individual sentences, several sentences together or complete paragraphs, text segments must be delimited flexibly rather than by means of a fixed analytic unit. The content analysis was made with a flexible coding to determine the different learning experiences people had and the different ways in which they would express the effects of the course. The categories do not exclude each other at the individual level. Instead, in the written responses individual teachers may have described several concepts. Phenomenography does not aim to discover different types of individuals, but rather different forms of understanding phenomena and the concepts that individuals express.

Accordingly, the unit of analysis was not identified on an individual basis in the first phase. All writings/open answers were handled as a whole to determine 'the most important pool of meanings' in their descriptions. As the focus is on teachers' conceptions of the most meaningful learning effects to promote their teaching, the first step of the analysis was to identify the passages that they discussed and what areas they found to be most important in their learning. The extracts were tagged with the themes of the teacher's personality, pedagogical issues and learning environment issues. After this phase, in the analysis of the data, the selected extracts were examined in greater detail. The writings were repeatedly read in order to determine the distinct ways in which the teachers described the most valuable learning experiences for their development. These areas could be classified into the categories of emotions, motivation and creativity. When two expressions included the same meaning, they were placed into the same category. After placing the extracts into the themed categories, the attributes and features of the categories were identified and compared in a detailed analysis. 


\section{Results}

According to content analyses of the results of post-evaluation, the responses can be seen in Table 1.

Three themes were related to emotions, motivation and creativity. These themes are classified according to three different educational aspects: teachers' personality, pedagogical issues and environmental issues, including sustainable developmental issues. We can provide several main points clearly characterising the effect of the course on the teacher's personality, pedagogical issues, learning environment and sustainable issues as participant teachers have themselves described.

Table 1 . The course effect on teachers' personality, pedagogical issues and learning environment in emotions, motivation and creativity categories

\begin{tabular}{llll}
\hline & Emotions & Motivation & Creativity \\
\hline Teacher's personality & $\begin{array}{l}11 / 11 \\
\text { recognition } \\
\text { of emotions; } \\
\text { expression of } \\
\text { emotions }\end{array}$ & $\begin{array}{l}11 / 11 \\
\text { efforts for active learning; } \\
\text { different ways of working }\end{array}$ & $\begin{array}{l}7 / 11 \\
\text { increase in trying new } \\
\text { meds }\end{array}$ \\
\hline $\begin{array}{llll}\text { Pedagogical issues } \\
\text { recognise the role } \\
\text { of emotions in } \\
\text { learning and teaching }\end{array}$ & $\begin{array}{l}\text { learning as fun leads to } \\
\text { better results; } \\
\text { change in teaching } \\
\text { methods to motivate } \\
\text { pupils }\end{array}$ & $\begin{array}{l}\text { use new techniques; } \\
\text { use art for better } \\
\text { results; } \\
\text { plan more creative } \\
\text { lessons }\end{array}$ \\
\hline $\begin{array}{l}\text { Learning environment } \\
\text { and sustainability issues }\end{array}$ & $\begin{array}{l}\text { lo/11 } \\
\text { create a positive } \\
\text { emotional working } \\
\text { atmosphere }\end{array}$ & $\begin{array}{l}\text { use different learning } \\
\text { environments and nature } \\
\text { to motivate pupils }\end{array}$ & $\begin{array}{l}\text { use new tools to create } \\
\text { a better classroom } \\
\text { climate; } \\
\text { introduce new, creative } \\
\text { rituals in school }\end{array}$ \\
\hline
\end{tabular}

Questions about the effects were asked six months after the course. As the results show, the greatest effect was on the teacher's personality. On the other hand, the teacher's personality is the tool for his/her work, so the effect can also be seen in the teaching methods and in the learning environments and the issues of sustainable development.

I think this course developed my emotional intelligence. After this course, I recognise and identify my emotions much better; I understand the causes of my feelings and handle emotions in myself and in others. Now, I think more positively about myself and other people, I became more optimistic and empathetic. I talk less and listen more. I certainly will try to educate myself emotionally in the future (a female teacher, Lithuania).

Another teacher also noticed an increase in optimism and positive attitudes after the course.

For my personal life, I got an energy boost that lasted for a long time. When times were hard, I could remember how warm the group atmosphere was. I also try to implement the positive mentality in my personal life. In the course of the months, an e-mail conversation developed with two other participants, which also enriched my personal life (a female teacher, Belgium). 
In this teacher's comments, we see a slighly different reaction to the course as she considers how her students will react.

I feel stronger! Before the course, I was persuaded that active learning methods were 'bliss' for our students who have difficulties with the traditional way of learning. The course has helped me to talk about these methods and insist on applying them (a female teacher, France).

Another teacher attributed the success of the programme to the setting and companionship that was felt among the teachers in the group.

Besides so much fun and a very meaningful week, I have so many happy memories. I got many new ideas on how to work. Most important was the feeling in the group. The teacher used the week in an excellent way to create security and harmony in the group. The discussions and practices we were doing had such a deep effect because of this group feeling. Now, when I plan my work in school and church, I have this fresh in my memory. Unfortunately, the circumstances are seldom so wonderful where I do my work (the conference was in sunny Cyprus, with good food and devoted and open-minded people) compared to the course situation (a male teacher, Sweden).

Finally, a teacher from Finland could immediately see the correlation between the workshop and her teaching situation at home.

I got more energy for myself and my work because of all those new things I learned in the course. I got more courage for my profession as a teacher because the positive support in our group was really amazing. I learned to read my pupils more effectively because I'm focused more on watching their motivation and their emotional state. I also pay more attention to my colleagues at work (a female teacher, Finland).

All of the teachers have used at least some of the methods and all of them have had positive experiences and results in using them. Teachers have been encouraged to use creative methods or at least to try something new and different.

My students liked the "Dream City" exercise very much. They really surprised me. For example, one boy who has serious problems with self-regulation, in the process, became a peacemaker in his group. It was a good experience for him, his group and me. After the art workshop, he said it was his best day in school ever. When we had reflection, I was surprised how children named and analysed their positive and negative feelings, what serious conclusions they had about emotions in themselves and others. I did not expect that 8- to 9-year-old children could have such a high-level ability to analyse their emotions (a female teacher, Lithuania).

This teacher has changed her curriculum based on what she learned in the programme.

I don't really teach grammar anymore. Instead, I let the students find grammatical structures by playing the games mentioned above (a female teacher, Denmark).

Most of the teachers have been able to disseminate the methods to the entire school, but two 
of them reported that it had not been possible. One teacher said she waits and hopes that her colleagues will observe and notice what she does and, thus, become interested in the new methods, while another said that only two from his 58 colleagues have become interested and started to use the methods whereas the others think they are a waste of time. The other nine teachers had better experiences; in any case, the school culture and the support and attitude of the headmaster also play an important role in the dissemination of new ideas.

The classroom climate has improved. The children beg and want me to do the exercises with them. My experience also meant some benefit for the school since I practised several exercises at the Open Door Day in November. I worked with pupils I usually don't teach, and they were enthusiastic about the exercises. Moreover, many colleagues watched me that day and are also copying the exercises now (a female teacher, Germany).

Right after the course, all of the participants were willing to share the experience with somebody, mostly with their colleagues, headmasters, school parents and friends, but also with the other schools in their region. The post-evaluation answers indicate that this has actually happened, and, at its best, the participation of one teacher may indeed benefit the entire school community.

\section{Conclusions and discussion}

The evaluation of the effects of the training course for teachers' personality and professional life indicates that, in a one-week intensive European training, it is possible:

- to make changes in teaching methods;

- to develop emotional intelligence;

- $\quad$ to improve creativity;

- to improve sustainable development through education.

The study not only proves that the learned methods support sustainability, but also confirms the premise that staff development can build teachers' emotional health and support of one another as well as encourage students' creativity, their ideas and choices. Together these elements contribute to a positive emotional climate in schools that ultimately enriches communities and the world.

Dissemination is essential in the EU-funded programmes; it is an integral part of the entire project and should be implemented on an ongoing basis. In this case study project, the partners who created the course shared their expertise and methods, and, from this source, the pilot training course was developed. Sustainability is the capacity of the project to continue its existence and function beyond the end of the funded period (Bienzle, 2010). The process is still ongoing, and, as long as there are applicants to the course, it is also possible to apply for funding and continue organising it.

The methods that were used in Finland were the bases of the European courses after the project. Since there have already been 30 courses organised and the participants came from 31 countries, this widespread use of the methods indicates ways of exploitation of the results, 
which is part of the dissemination.

\section{References:}

Azevedo, R., \& Cromley, J. G. (2004). Does training on self-regulated learning facilitate students' learning with hypermedia? Journal of Educational Psychology, 96, 523-535.

Bienzle, H. (2010). Survival kit, managing multilateral projects in the Lifelong Learning Program. Retrieved June 16, 2011, from www.european-project-management.eu

Butler, D. L., \& Cartier, S. (2004). Promoting students' active and productive interpretation of academic work: A key to successful teaching and learning. Teachers College Record, 106, 1729-1758.

Deci, E. L., \& Ryan, R. M. (1985). Intrinsic motivation and self determination in human behavior. New York: Plenum Press.

Dewey, J. (1997/1938). Experience and education. New York: Touchstone.

Fleer, M. (2002). Curriculum compartmentalization? A futures perspective on environmental education. Environmental Education Research, 8(2), 137-154.

Gardner, H. (1993). Frames of mind: Theory of multiple intelligences. London: Fontana Press.

Hopkins, C., \& Mackeown, R. (2002). Education for sustainable development: An international perspective. In D. Tilbury, R. B. Stevenson, J. Fien \& D. Schreuder (Eds.), Education and sustainability (pp. 13-24). Cambridge: IUCN.

Marton, F. (1994). Phenomenography. In T. Hussén \& T. N. Postlethwaite (Eds.), The international encyclopaedia of education (2nd ed.). (Vol. 8, pp. 4424-4429). Oxford: Pergamon.

Pajares, F. (1992). Teachers' beliefs and educational research: Cleaning up a messy construct. Review of Educational Research, 62, 307-332.

Pintrich, P. R. (2000). Multiple goals, multiple pathways: The role of goal orientation in learning and achievement. Journal of Educational Psychology, 92, 544-555.

Randi, J. (2004). Teachers as self-regulated learners. Teachers College Record, 106(9), 18251853.

Randi, J., \& Corno, L. (2000). Teacher innovations in self-regulated learning. In P. Pintrich, M. Boekaerts \& M. Zeidner (Eds.), Handbook of self-regulation (pp. 651-685). Orlando, FL: Academic Press.

Ryan, R. M., \& Deci, E. L. (1985). Intrinsic motivation and self determination in human behavior. New York: Plenum Press.

Salovey, P., Bedell, B. T., Detweiler, J., \& Mayer, J. D. (2004). Current directions in emotional intelligence. In M. Lewis \& J. Haviland-Jones (Eds.), Handbook of emotions (pp. 504-522). New York: Guilford Press.

Saphier, J., \& King, M. (1985). Good seeds grow in strong cultures. Educational Leadership, 

$42(6), 67-74$.

Schraw, G., Crippen, K. J., \& Hartley, K. (2006). Promoting self-regulation in science education: Metacognition as part of a broader perspective on learning. Research in Science Education, 36, 111-139.

Steiner, G., \& Posh, A. (2006). Higher education for sustainability by means of transdiciplinary case studies: An innovative approach for solving complex, real-world problems. Journal of Cleaner Production. Sustainability in Higher Education: What is Happening? 14(9-11), 877-890.

White, R. (2001). Transforming teaching: The project for enhancing effective learning. Unterrichtswissenschaft [The Science of Education], 29(3), 213-223.

Zimmerman, B. J. (1990). Self-regulated learning and academic achievement: An overview. Educational Psychologist, 25, 3-17.

Zimmerman, B. J. (2000). Self-efficacy: An essential motive to learn. Contemporary Educational Psychology, 25, 82-91.

\section{Correspondence:}

Ulla Salomaki, PhD student, Teuvo Pakkalantie 12 F 8300400, Helsinki. Email: ulla.salom aki@kolumbus.fi; ulla.salomaki@helsinki.fi 